\title{
A 55-year-old male immigrant with lymphoma and Gram-negative sepsis
}

\author{
Omar N Nadhem MD¹, Mohammed Bahaa-Al-Deen MD¹, Mansoor Mehmood MD ${ }^{1}$, Faisal A Khasawneh MD²
}

\begin{abstract}
CASE PRESENTATION
A 55-year-old male immigrant from Iraq presented with progressive shortness of breath and hypotension. The illness started with diarrhea and headache, and began three weeks after the first cycle of chemotherapy (cyclophosphamide, doxorubicin, vincristine and prednisone) was administered for the patient's newly diagnosed lymphoma. On presentation, he was in septic shock and respiratory failure requiring mechanical ventilation. The patient had altered sensorium and neck rigidity. He had no rashes and no lymphadenopathy. His white blood cell count was $16.9 \times 10^{9}$ cells/L with $8 \%$ eosinophilia. Chemistry tests showed acute kidney injury with a creatinine level of $168.0 \mu \mathrm{mol} / \mathrm{L}$. Chest $\mathrm{x}$-ray showed multilobar pneumonia. His blood and sputum cultures grew Escherichia coli. Lumbar puncture performed $24 \mathrm{~h}$ after presentation showed pleocytosis and elevated protein level; however, the culture was negative. A diagnostic test was performed.

What is your diagnosis?
\end{abstract}

\section{DIAGNOSIS}

A stool wet mount was performed and revealed Strongyloides larvae (Figure 1). He was diagnosed with E coli septic shock incited by Strongyloides hyperinfection and dissemination. Chemotherapy, particularly steroids, was the trigger behind this syndrome. Despite aggressive supportive measures including ivermectin, the patient succumbed to multiorgan failure in the second week of his illness.

\section{DISCUSSION}

There are $>50$ species of Strongyloides, with Strongyloides stercoralis (threadworm) being the most common in humans (1). These helminthes affect millions of individuals worldwide and are most endemic in tropical and subtropical regions of the globe (2). The majority of reported infections in North America occur in immigrant populations; however, sporadic cases have been reported in the southeastern regions of the United States (3).

Infection begins when the filariform larva penetrates the skin (4). This event usually goes unnoticed although, on occasion, the patient may report localized, pruritic, erythematous, papular rash soon after larval penetration (larva currens). The larvae hematogenously spread to the lungs, where they migrate to the tracheobronchial tree, are coughed up and swallowed. Invasion of the lungs can cause asthmalike symptoms and pneumonitis. In the small intestine, the larvae burrow in the mucosa and molt twice to become adult worms. Through parthenogenesis, the adult female worm produces eggs that hatch into rhabditiform larvae, subsequently migrate to the colon and are mostly excreted in feces (4). Infection of the gastrointestinal (GI) tract is asymptomatic, although some patients may report nonspecific symptoms such as nausea and chronic diarrhea. A small percentage of the larvae mature into infective filariform larvae, which penetrate the colonic mucosa or perianal skin and reinfect the host. Larva currens is more likely to occur at the time of reinfection as opposed to the time of original infection. This cycle of maturation and autoinfection within the host leads to the persistence of this infection and may last for decades (4). It is worth mentioning that Strongyloides is the only clinically important helminthic parasite that can complete its entire life cycle within the human host (4).

Chronic $S$ stercoralis infection is often asymptomatic and rarely presents with the nonspecific dermatological, GI or pulmonary symptoms described above (5). It carries low mortality unless the host's immunity wanes and, subsequently, the parasitic infestation progresses to more serious forms of infection (hyperinfection syndrome and/or disseminated disease) (5). The above two entities can be distinguished as follows.

In hyperinfection, the parasite burden increases and the cycle of autoinfection accelerates; however, the Strongyloides larvae continue to be confined to the organs normally involved in the autoinfection cycle (ie, GI tract and lungs). Severe GI symptoms, including abdominal pain, intestinal obstruction and ileus, may occur, and severe bronchospasm and acute respiratory failure requiring mechanical ventilation have been reported (6-9).

On the other hand, disseminated disease results from the migration of Strongyloides larvae to organs beyond the GI tract and lungs such as the brain, liver, kidneys and skin. Dissemination carries a formidable risk for morbidity and mortality (5). As the worm burrows through the intestinal mucosa, it carries with it colonic commensal organisms, mainly Gram-negative bacteria and, rarely, Gram-positive bacteria, such as Streptococcus bovis, and Candida (10). This causes bacteremia, meningitis and other secondary infections and, consequently, contributes to organ damage.

Risk factors that are known to promote the evolution of strongyloidiasis to hyperinfection syndrome and/or disseminated disease include: immunosuppressive therapy and the use of steroids in particular; hematological malignancies, especially lymphoma, bone marrow and renal transplantation; human T cell lymphotropic virus type 1 infection; HIV infection; hypogammaglobulinemia; and malnutrition $(11,12)$

Strongyloidiasis is largely unrecognized due to the low level of clinical suspicion and the low sensitivity of diagnostic tools (6). Eosinophilia is common in asymptomatic and symptomatic cases but is nonspecific (7). The diagnostic sensitivity of examining three stool samples for $S$ stercoralis is approximately 50\% (13). Strongyloides serology testing is available, with a reported sensitivity of $80 \%$ to $97 \%$ (14). Unfortunately, it cannot differentiate between previous, active or treated infections, although assessing trends in titres may be useful. Furthermore, it can be falsely negative in immunocompromised patients and falsely positive in the presence of other helminthic infections (15). In addition to the abovementioned tests, filariform larvae multiply exponentially in hyperinfection syndrome, and respiratory

${ }^{1}$ Department of Internal Medicine; ${ }^{2}$ Section of Infectious Diseases, Department of internal medicine, Texas Tech University Health Sciences Center, Amarillo, Texas, USA

Correspondence: Dr Faisal A Khasawneh, Section of Infectious Diseases, Department of Internal Medicine, Texas Tech University Health Sciences Center, 1400 South Coulter Street, Amarillo, Texas 79106, USA. Telephone 806-690-7074, fax 806-354-5765,

e-mail faisal.khasawneh@ttuhsc.edu

OPEN $\bigcirc$ ACCESS

This open-access article is distributed under the terms of the Creative Commons Attribution Non-Commercial License (CC BY-NC) (http:/ creativecommons.org/licenses/by-nc/4.0/), which permits reuse, distribution and reproduction of the article, provided that the original work is properly cited and the reuse is restricted to noncommercial purposes. For commercial reuse, contact support@pulsus.com 


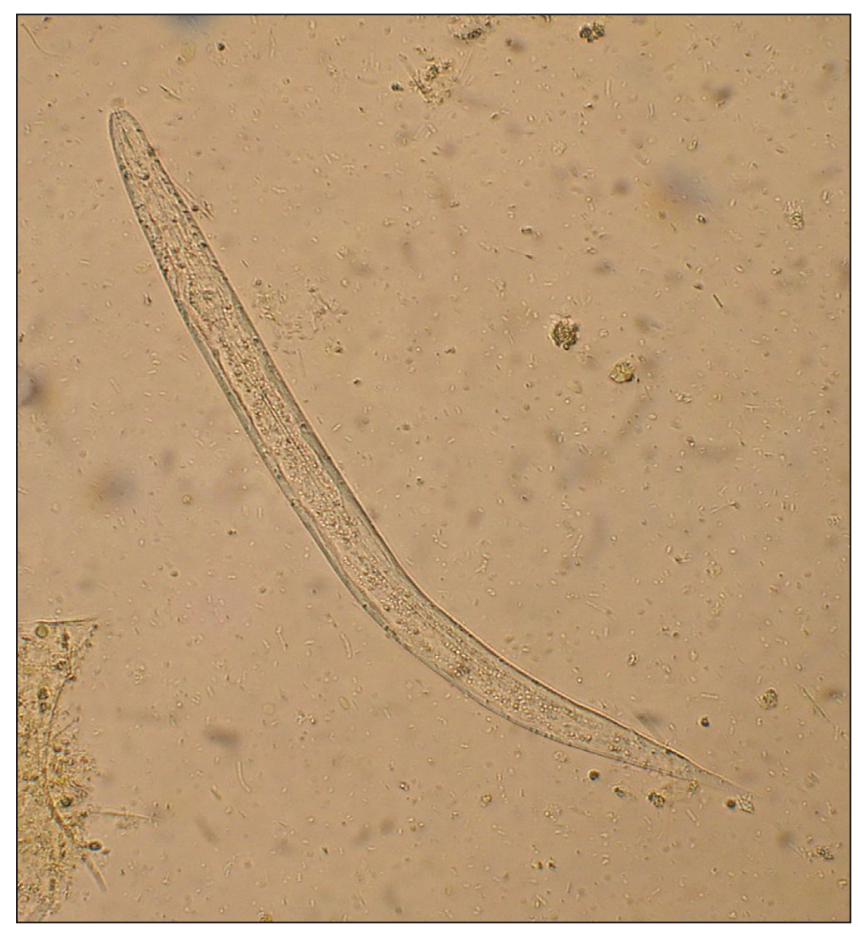

Figures 1) Stool wet mount showing Strongyloides stercoralis larvae. Original magnification $\times 40$

\section{REFERENCES}

1. Speare R. Identification of species of Strongyloides. In: Grove DI, ed. Strongyloidiasis: A major roundworm infection of man. London: Taylor and Francis, 1989:11-83.

2. Genta RM. Global prevalence of strongyloidiasis: Critical review with epidemiologic insights into the prevention of disseminated disease. Rev Infect Dis 1989;11:755-67.

3. Lim S, Katz K, Krajden S, Fuksa M, Keystone JS, Kain KC. Complicated and fatal strongyloides infection in Canadians: Risk factors, diagnosis and management. CMAJ 2004;171:479-84.

4. Smith JD, Goette DK, Odom RB. Larva currens. Cutaneous strongyloidiasis. Arch Dermatol 1976;112:1161-3.

5. Keiser PB, Nutman TB. Strongyloides stercoralis in the immunocompromised population. Clin Microbiol Rev 2004;17:208-17.

6. Mahmoud AA. Strongyloidiasis. Clin Infect Dis 1996;23:949-52; quiz, 53.

7. Boulware DR, Stauffer WM, Hendel-Paterson BR, et al. Maltreatment of Strongyloides infection: Case series and worldwide physicians-intraining survey. Am J Med 2007;120:545, e1-8.

8. Csermely L, Jaafar H, Kristensen J, et al. Strongyloides hyper-infection causing life-threatening gastrointestinal bleeding. World J Gastroenterol 2006;12:6401-4.

9. Hindy P, Parvin R, Hanna K, Gress F. Strongyloidiasis presenting as duodenal obstruction in a patient infected with human T-cell lymphotropic virus type 1. Gastrointest Endosc 2011;74:439-41.

10. Newberry AM, Williams DN, Stauffer WM, Boulware DR, Hendel-Paterson BR, Walker PF. Strongyloides hyperinfection fluid, peritoneal fluid, blood, bone marrow and cerebrospinal fluid should be examined for the presence of larvae $(8,13)$.

Untreated hyperinfection syndrome is fatal and mortality remains $>25 \%$ even with optimal therapy (16). Ivermectin is the drug of choice, with reported eradication rates of $80 \%$ (17). It is advisable to repeat the two-day course one week after the initial course with follow-up. Thiabendazole and albendazole are acceptable, although less effective, alternatives. Treatment efficacy can be documented after two weeks by examining the stool or the fluid of the upper small bowel for larvae (3). The trend in anti-Strongyloides antibody titres can also be used to confirm the adequacy of treatment (3). Furthermore, patients with $S$ stercoralis hyperinfection are infectious and contact precautions are recommended to prevent nosocomial transmission (13).

Therapeutic failures are more common in immunosuppressed patients, and some experts recommend longer courses of treatment or albendazole and ivermectin combination therapy in this patient population (3). In the case of disseminated infection, albendazole and ivermectin may be continued until there is evidence of complete parasitic clearance (3).

Although there are no standard recommendations for screening patients for strongyloidiasis, it appears to be reasonable to screen patients at high risk for hyperinfection syndrome (14). Patients who have unexplained eosinophilia or who migrated from or travelled to endemic areas should be screened with serological testing for Strongyloides before initiating immunosuppressive therapy. Patients with positive serology can be treated empirically with ivermectin $(3,5)$.

DISCLOSURES: The authors have no financial support or conflicts of interest to declare.

presenting as acute respiratory failure and gram-negative sepsis. Chest 2005;128:3681-4.

11. Vadlamudi RS, Chi DS, Krishnaswamy G. Intestinal strongyloidiasis and hyperinfection syndrome. Clin Mol Allergy 2006;4:8.

12. Marcos LA, Terashima A, Dupont HL, Gotuzzo E. Strongyloides hyperinfection syndrome: An emerging global infectious disease. Trans R Soc Trop Med Hyg 2008;102:314-8.

13. Nielsen PB, Mojon M. Improved diagnosis of Strongyloides stercoralis by seven consecutive stool specimens. Zentralbl Bakteriol Mikrobiol Hyg A 1987;263:616-8.

14. Gyorkos TW, Genta RM, Viens P, MacLean JD. Seroepidemiology of Strongyloides infection in the Southeast Asian refugee population in Canada. Am J Epidemiol 1990;132:257-64.

15. Page WA, Dempsey K, McCarthy JS. Utility of serological follow-up of chronic strongyloidiasis after anthelminthic chemotherapy. Trans R Soc Trop Med Hyg 2006;100:1056-62.

16. Reddy IS, Swarnalata G. Fatal disseminated strongyloidiasis in patients on immunosuppressive therapy: Report of two cases. Indian J Dermatol Venereol Leprol 2005;71:38-40.

17. Datry A, Hilmarsdottir I, Mayorga-Sagastume R, et al. Treatment of Strongyloides stercoralis infection with ivermectin compared with albendazole: Results of an open study of 60 cases. Trans R Soc Trop Med Hyg 1994;88:344-5. 


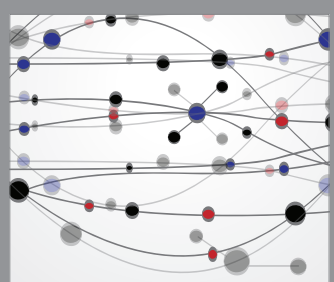

The Scientific World Journal
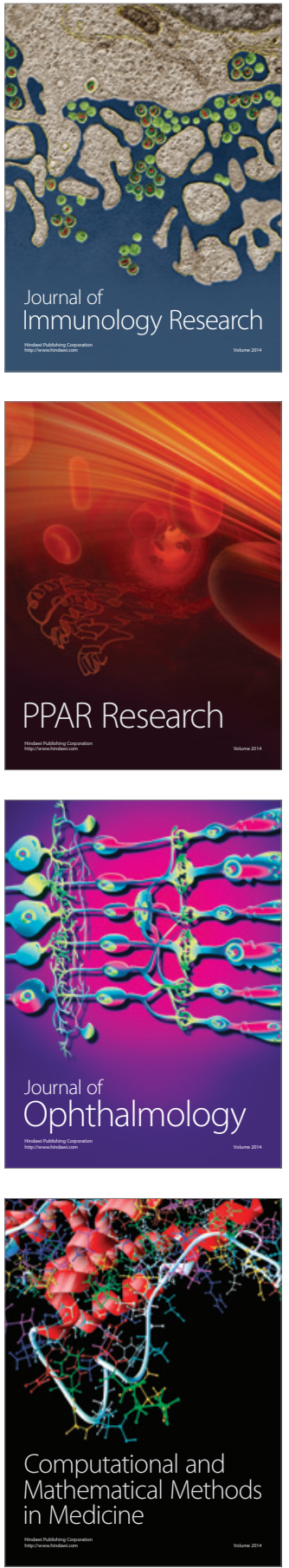

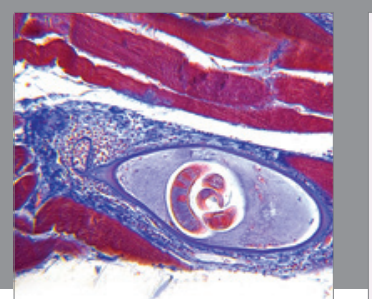

Gastroenterology Research and Practice

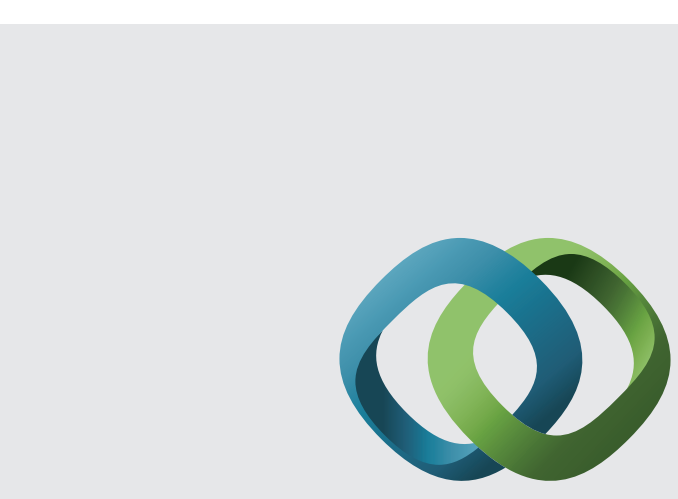

\section{Hindawi}

Submit your manuscripts at

http://www.hindawi.com
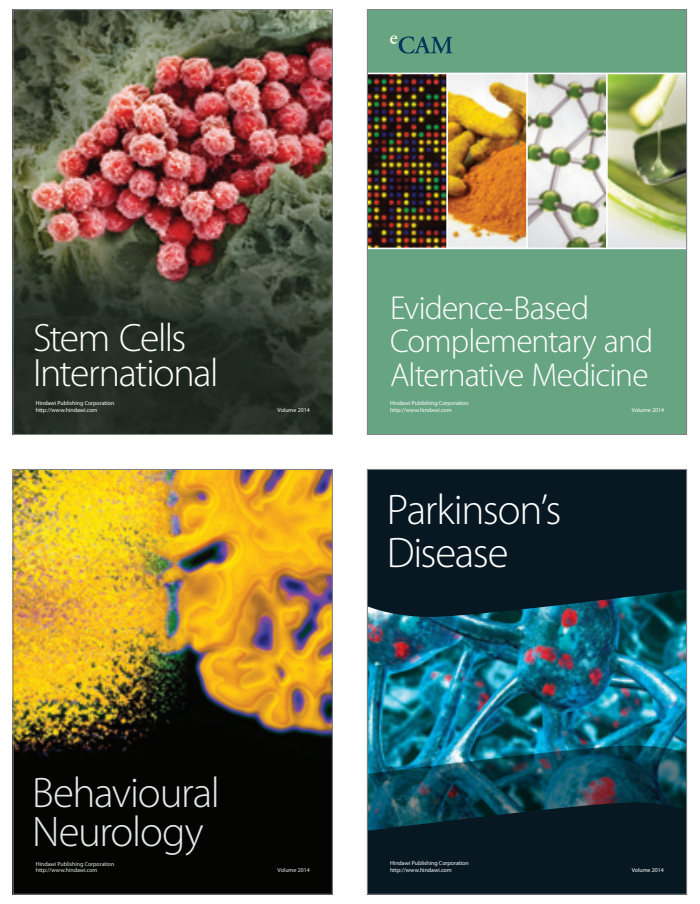
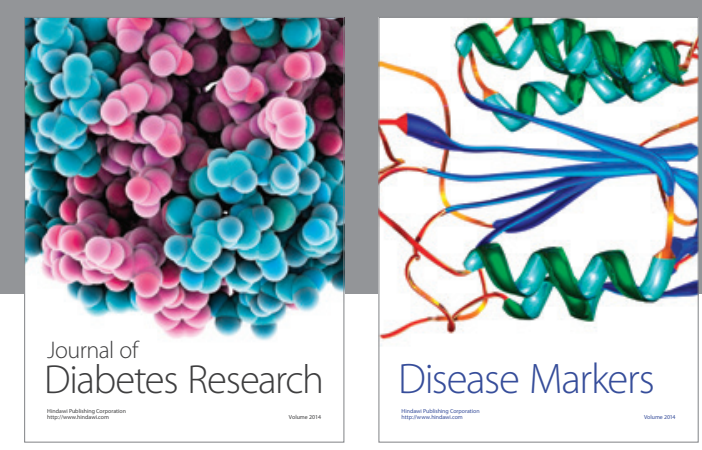

Disease Markers
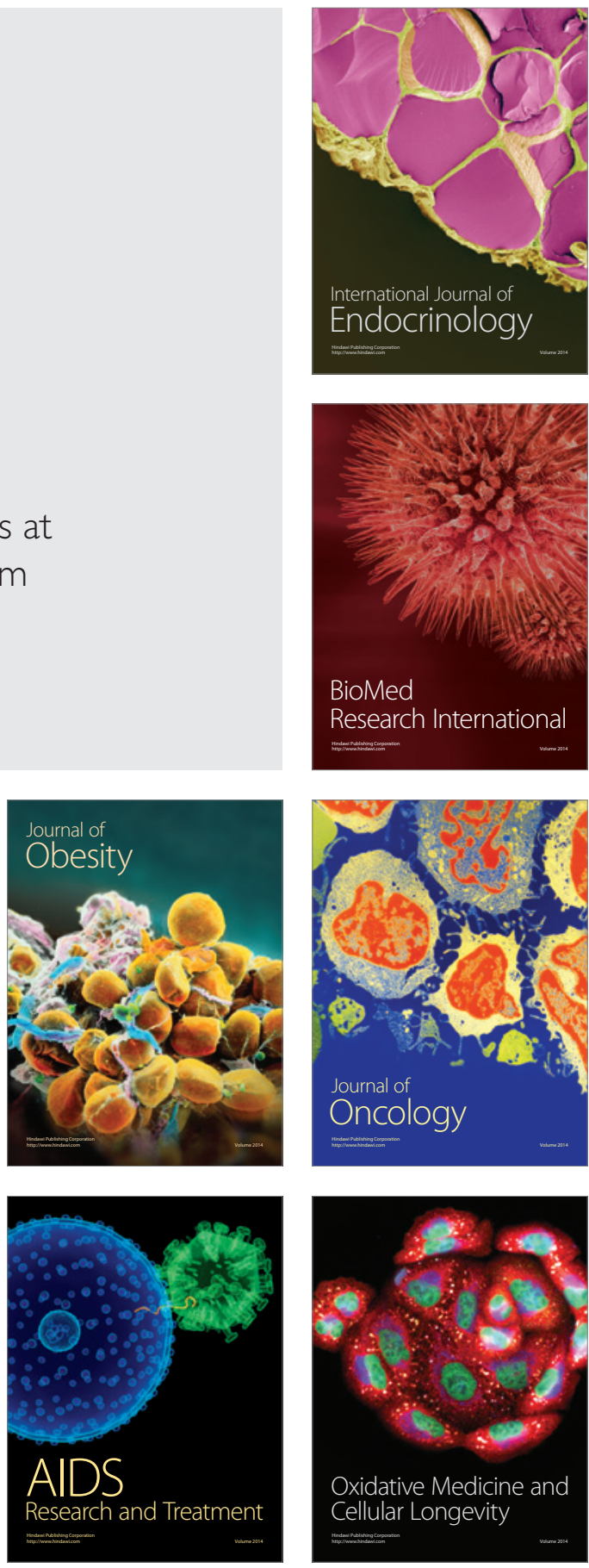